\title{
Economic burden of pediatric prescription opioid poisonings in the United States
}

\author{
Anisha M Patel, PhD, MS; Norman V Carroll, PhD, MS, BSPharm; David C Wheeler, PhD, MPH, MS, MA, BA; \\ S Rutherfoord Rose, PharmD, FAACT, BSPharm, BA; Pramit A Nadpara, PhD, MS, BPharm; \\ Amy L Pakyz, PhD, MS, PharmD, BSPharm, BS; and Stephen C Ijioma, PharmD, BA
}

\section{What is already known about this subject}

- Although pediatric fatalities related to unintentional drug poisonings have decreased over the years, the number of pediatric unintentional drug exposures and poisonings reported to poison centers and the associated morbidity (i.e., rates of emergency department [ED] visits and hospital admissions and rates of injury) have risen.

- Some studies have examined the economic burden of opioid poisoning in the general population (including adults), but very little is known about the pediatric population.

- Presentation of opioid poisonings in children can differ from adults.

\section{What this study adds}

- This study examines the economic burden of opioid poisonings in pediatric patients by examining direct and indirect costs.

- Indirect costs associated with pediatric prescription opioid poisonings are substantial due to the productivity losses incurred, and total inpatient costs were about twice the total ED costs.

- Pediatric prescription opioid poisoningrelated ED visits, inpatient stays, and deaths were most common in patients aged $13-17$ years and those in mid to large urban areas; most were unintentional.

\section{Author affiliations}

Anisha M Patel, PhD, MS, BPharm, Department of Pharmacotherapy \& Outcomes Science; Norman V Carroll, PhD, MS, BSPharm, Department of Pharmacotherapy \& Outcomes Science; David C Wheeler, PhD, MPH, MS, MA, BA, Department of Biostatistics; $S$ Rutherfoord Rose, PharmD, FAACT, BS Pharm, BA, Department of Emergency Medicine; Pramit A Nadpara, PhD, MS, BPharm, Department of Pharmacotherapy \& Outcomes Science; Amy L Pakyz, PhD, MS, PharmD, BSPharm, BS, Department of Pharmacotherapy \& Outcomes Science (deceased); and Stephen C Ijioma, PharmD, BA, Department of Pharmacotherapy \& Outcomes Science, Virginia Commonwealth University, Richmond.

AUTHOR CORRESPONDENCE:

Stephen ljioma, 919.599.5046,

ijiomas@vcu.edu

\section{J Manag Care Spec Pharm 2021;27(1):16-26 \\ Copyright $\odot 2021$, Academy of Managed Care Pharmacy. All rights reserved.}

atric or nervous system disorders such as agitation, seizures, and coma; and cardiac disorders such as tachycardia, bradycardia, and cardiac arrest. Opioid poisonings in children can have delayed onset of symptoms as well as severe and prolonged toxic effects. Many studies have examined the economic burden of opioid poisoning in the general population, but very little is known about the pediatric population.
OBJECTIVE: To estimate the economic burden associated with pediatric prescription opioid poisonings.

METHODS: This study examined opioid poisonings in pediatric patients, defined as patients aged less than 18 years, for the 2012 base year. Costs were estimated using the 2012 Nationwide Emergency Department Sample (NEDS), Kids' Inpatient Database (KID), Multiple Cause-of-Death (MCOD) file, 
and other published sources, while applying a societal perspective. The Bottom Up approach was used to estimate the total cost of pediatric prescription opioid poisonings. Direct costs included costs associated with emergency department (ED) visits, hospitalizations, and ambulance transports. Indirect costs were estimated using the human capital method and included productivity costs due to caregivers' absenteeism and premature mortality among children. Descriptive statistics were employed in calculating costs.

RESULTS: The total costs of pediatric prescription opioid poisonings and exposure in the United States were $\$ 230.8$ million in 2012. Total direct costs were estimated to be over $\$ 21.1$ million, the majority resulting from prescription opioid poisoning-related inpatient stays. Total indirect (productivity) costs were calculated at \$209.7 million, and $98.6 \%$ of these costs were attributed to opioid poisoning-related mortality. Pediatric prescription opioid poisoning-related ED visits, inpatient stays, and deaths were most common in patients aged 13-17 years and those in mid to large urban areas. Most were unintentional.

CONCLUSIONS: Pediatric prescription opioid poisonings resulted in direct and indirect costs of $\$ 230.8$ million in 2012 . While these costs are low in comparison with the costs of prescription opioid poisoning in the general population, the number of pediatric poisonings represents only a small fraction of total poisonings. Quantified costs associated with pediatric prescription opioid poisonings can help decision makers to understand the economic trade-offs in planning interventions.

The Centers for Disease Control and Prevention reported that drug overdoses increased more than 4 times between 1999 and 2017. About 399,230 people died from an overdose involving a prescription or illicit opioid during this time period. In 2017 alone, more than 70,000 people died from drug overdoses in the United States, and about $68 \%$ of these involved a prescription or illicit opioid., ${ }^{1,2}$ In the pediatric population, prescription and illicit opioid-related mortality rates increased from 0.22 to 0.81 per 100,000 between 1999 and 2016, an increase of $268.2 \%{ }^{3}$ The 5-year prevalence rates of pediatric prescription opioid exposures from 2010 to 2014 was 22.6 per 100,000 children and decreased from 25.5 to 20 per 100,000 children. During this time, the pediatric prescription opioid poisonings rate was 11.8 per 100,000 children. ${ }^{4}$

Opioid poisonings involve an opioid exposure resulting in a corresponding clinical symptom or medical effect. ${ }^{4}$ They often result in symptoms such as respiratory depression and are typically managed with opioid antagonists and oxygen supplementation. ${ }^{5}$ According to the Council of Economic Advisers, the total economic burden of the opioid crisis in the United States was estimated to be $\$ 696$ billion in 2018, 3.4\% of the gross domestic product, and over \$2.5 trillion from 2015 to 2018 . These estimates include "the value of lost lives, as well as increases in healthcare and substance abuse treatment costs, increases in criminal justice costs, and reductions in productivity." According to Gaither et al. (2016), about 8,986 children and adolescents died from prescription and illicit opioid poisonings between 1999 and 2016. ${ }^{3}$ Pediatric hospitalization rates increased by 2 -fold across age all groups between 1997 and 2012, and the number of pediatric opioid-related hospitalizations requiring critical care doubled from 797 in 2004 to 1,504 in 2015.,3,8 Yokell et al. (2014) examined mean charges for emergency department (ED) visits in 2010 U.S. dollars. ${ }^{9}$ They reported 92,209 ED visits for prescription opioid poisonings with a mean charge of $\$ 3,640$. A total of 4,998 visits were for pediatric patients.

The epidemiology, health care resources use (HCRU), and costs of opioid poisonings can vary based on age. ${ }^{9}$ Despite the data on the economic burden of the opioid crisis in the general population, very little is known about the total economic burden of opioid poisonings, specifically, in the pediatric population. As a result, the objective of this study was to estimate the direct and indirect costs associated with pediatric prescription opioid poisonings. We defined pediatric patients as those aged less than 18 years.

\section{Methods}

This was a retrospective, cross-sectional study that applied a societal perspective. Study data came from the Healthcare Cost and Utilization Project (HCUP) 2012 Nationwide Emergency Department Sample (NEDS), the 2012 Kids' Inpatient Database (KID), and the National Vital Statistics System's 2012 Mortality Multiple Cause-of-Death (MCOD) files. The NEDS is the largest all-payer ED database in the United States. It captures information on all ED visits including those that resulted in hospital admissions. ${ }^{10}$ The KID is the largest publicly available all-payer pediatric inpatient care database in the United States. It yields national estimates on inpatient stays for patients aged younger than 21 years. ${ }^{11}$ The MCOD is a county-level mortality and population database that provides information on demographics and the underlying cause of all deaths among U.S. residents, including pediatric patients..$^{12}$ NEDS and KID are samples of the relevant populations that include hospital-level weights that allow the researcher to develop nationally representative estimates. To do so, each observation (ED or hospital visit) is multiplied by its respective weight. MCOD does not need weights to provide nationally representative estimates because it records all U.S. deaths. 
Discharge records from NEDS and KID were extracted for pediatric patients with 1 or more opioid poisoningrelated International Classification of Diseases, Ninth Revision, Clinical Modification (ICD-9-CM) diagnosis codes in any listed diagnosis field (965.00, 965.02, 965.09, E850.1, E850.2, or E950.0). Several studies have used data from NEDS and KID databases in a similar manner to evaluate prescription opioid abuse-related events, including opioid poisonings. ${ }^{13-16}$ Intentionality of opioid poisonings was identified as unintentional, intentional, or undetermined using these ICD-9-CM codes (E-codes). Data are recorded for up to 4 E-codes for each visit or stay. Records that did not have a specific E-code were initially classified as missing. This resulted in about $7 \%$ of ED visits with a missing or unknown intentionality in NEDS. However, NEDS contains certain injury-related variables including intent (self-harm or unintentional) on every record. Information from these injury-related variables was used to impute intentionality to the extent possible. For instance, if the record was classified as undetermined (using E-code 980.0) or missing, but had an indicator for self-harm, then the record was reclassified as intentional. Such injury-related variables are not recorded in the KID, and inpatient stays that did not have a specific E-code were classified as unknown.

We estimated direct medical costs and indirect costs. Direct costs included costs associated with ED visits, hospitalizations, and ambulance transports. Indirect costs were estimated using the human capital method and included productivity costs due to caregivers' absenteeism and premature mortality among children. All cost calculations were made for the 2012 base year, since that was the most recent data available at the time of data acquisition. Costs from other years were adjusted to 2012 U.S. dollars (USD) using the Bureau of Labor Statistics' (BLS) medical care component of the Consumer Price Index or the BLS Employment Cost Index for civilian workers. ${ }^{17,18}$

Inpatient stay costs were obtained by multiplying inpatient charges with hospital-specific cost-to-charge ratios (CCR) provided by HCUP. ${ }^{19}$ NEDS does not provide CCRs for ED charges. However, HCUP has estimated ED CCRs by grouping hospitals by characteristics such as hospital ownership and location. We used these group average ED CCRs to convert ED charges to costs. ${ }^{19}$ Information on pediatric prescription opioid poisoning ED visits, inpatient stays, and deaths are shown in Table 1. The sample for ED visits was limited to discharges that did not result in hospital admission to avoid double counting. ED visits that resulted in hospitalization were captured in the inpatient data.

Costs of ED visits and inpatient stays included a facility charge and a physician charge. The facility charge covered all components of care, such as nursing services, rent and utilities, medications, and other supplies, except for physician charges. Total ED facility costs were calculated as the product of the total number of ED visits and the mean facility cost per visit. Physician costs were calculated by linking Current Procedural Terminology (CPT) codes from NEDS to the Centers for Medicare \& Medicaid Services (CMS) 2012 Physician Fee Schedule. ${ }^{20}$ The most common codes were for other diagnostic procedures (interview, evaluation, and consultation); other therapeutic procedures; microscopic examination (bacterial smear, culture, and toxicology); laboratory-chemistry and hematology; and medications (injections, infusions, and other forms). The sum of payment amounts for all CPT codes was calculated for each ED visit. Total ED costs were calculated as the sum of facility and physician costs. Outliers in ED charge data were examined (top/bottom 5\%). Upon manual inspection, these charges looked reasonable.

ED facility charges were missing for 182 (17.4\%) ED visits. We tried several different imputation methods for these missing data (Table 2). Imputation 1 set missing charges to zero based on the assumption that the observations with missing charges actually had zero charges. Imputation 2 set missing values to the mean of charges from nonmissing observations. Imputation 3 calculated the mean estimate of charges from subgroups of the sample. Subgroups were based on age group and intent of opioid poisoning. For instance, if the observation with missing charges was for a teenager with an intentional exposure, then the mean estimate of nonmissing ED charges of all teenagers with intentional exposure was imputed to that observation.

Imputation 4 used Markov Chain Monte Carlo (MCMC), a multiple imputation method, to impute missing charges. After examining the several imputation methods for missing data (Table 2), we used an MCMC method to impute missing charges for the base-case estimate of ED facility charges. The imputation model included child's age group; gender; median household income at ZIP-code level of residence location; type of opioid; intent; indicators for multi-drug poisonings, multi-injuries, and chronic conditions; number of diagnoses and procedures on record; disposition status; payer; hospital characteristics including hospital region, location, ownership, teaching status, and trauma status; and (nonmissing) ED physician cost.

CPT codes were missing for 340 (32.4\%) ED visits. Missing physician costs were imputed using techniques similar to those previously described (Table 2). MCMC was attempted but exhibited poor fit, so subset mean imputation was used for the base case. Subsets were based on age group and intent of poisoning.

Total inpatient facility costs were calculated as the product of the number of inpatient stays and the estimated 


\section{TABLE 1 Characteristics of Pediatric Prescription Opioid Poisoning ED Visits, Inpatient Stays, and Opioid Poisoning-Related Deaths}

\begin{tabular}{|c|c|c|c|c|c|c|c|}
\hline \multirow[b]{2}{*}{ Characteristics } & \multicolumn{2}{|c|}{$\begin{array}{l}\text { Pediatric Prescription Opioid } \\
\text { Poisoning ED Visits }\end{array}$} & \multicolumn{2}{|c|}{$\begin{array}{l}\text { Pediatric Prescription Opioid } \\
\text { Poisoning Inpatient Stays }\end{array}$} & \multicolumn{3}{|c|}{$\begin{array}{l}\text { Pediatric Prescription Opioid } \\
\text { Poisoning-Related Deaths }\end{array}$} \\
\hline & $\begin{array}{c}\text { Unweighted, } \\
\quad n(\%) \\
(n=1,048)\end{array}$ & $\begin{array}{c}\text { Weighted, } \\
n(\%) \\
(n=4,584)\end{array}$ & $\begin{array}{l}\text { Unweighted, } \\
\begin{array}{c}\mathbf{n}(\%) \\
(\mathbf{n}=1,334)\end{array}\end{array}$ & $\begin{array}{c}\text { Weighted, } \\
n(\%) \\
(\mathbf{n}=1,877)\end{array}$ & $\begin{array}{l}\text { Age Group } \\
\text { (years) }\end{array}$ & \multicolumn{2}{|c|}{ n (\%) } \\
\hline \multicolumn{8}{|l|}{ Sociodemographic } \\
\hline \multicolumn{8}{|l|}{ Age group (years) } \\
\hline $0<1$ & $48 \quad(4.6)$ & $208 \quad(4.5)$ & $102 \quad(7.6)^{b}$ & $(7.7)$ & - & \multicolumn{2}{|c|}{-} \\
\hline $1-2$ & $291 \quad(27.8)$ & $1,283 \quad(28.0)$ & $245 \quad(18.4)$ & $349 \quad(18.6)$ & - & \multicolumn{2}{|c|}{-} \\
\hline $3-5$ & $97 \quad(9.3)$ & $(9.2)$ & $64 \quad(4.8)$ & $92 \quad(4.9)$ & $\leq 5$ & 32 & $(26.0)$ \\
\hline $6-12$ & $49 \quad(4.7)$ & $(4.8)$ & $(5.1)$ & $(5.1)$ & $6-12$ & 5 & (4.1) \\
\hline $13-17$ & $563 \quad(53.7)$ & $2,448 \quad(53.4)$ & $855 \quad(64.1)$ & $1,196 \quad(63.7)$ & $13-17$ & 86 & $(69.9)$ \\
\hline \multicolumn{8}{|l|}{ Sex } \\
\hline Male & $484 \quad(46.2)$ & $2,149 \quad(46.9)$ & $595 \quad(44.6)$ & $839 \quad(44.7)$ & - & 88 & $(71.5)$ \\
\hline Female & $564 \quad(53.8)$ & $2,435 \quad(53.1)$ & $739 \quad(55.4)$ & $1,038 \quad(55.3)$ & - & 35 & $(28.5)$ \\
\hline \multicolumn{8}{|l|}{ Residence } \\
\hline Urban (mid to large) & $736 \quad(70.2)$ & $3,144 \quad(68.6)$ & $909 \quad(68.1)$ & $1,269 \quad(67.6)$ & - & \multicolumn{2}{|c|}{-} \\
\hline Urban (small to mid) & $237 \quad(22.6)$ & $1,076 \quad(23.5)$ & $333 \quad(25.0)$ & $472 \quad(25.2)$ & - & \multicolumn{2}{|c|}{-} \\
\hline Rural & $74 \quad(7.1)$ & $(7.8)$ & $90 \quad(6.8)$ & $(7.0)$ & - & \multicolumn{2}{|c|}{-} \\
\hline Unknown & $1 \quad(0.1)$ & $(0.1)$ & $(0.1)$ & $(0.2)$ & - & \multicolumn{2}{|c|}{-} \\
\hline \multicolumn{8}{|l|}{ Payer } \\
\hline Medicaid & $492 \quad(46.9)$ & $2,148 \quad(46.9)$ & $686 \quad(51.4)$ & $971 \quad$ (51.7) & - & \multicolumn{2}{|c|}{-} \\
\hline Private & $422 \quad(40.3)$ & $1,900 \quad(41.4)$ & $529 \quad(39.7)$ & $740 \quad(39.4)$ & - & \multicolumn{2}{|c|}{-} \\
\hline Other & $53 \quad(5.1)$ & $198 \quad(4.3)$ & $61 \quad(4.6)$ & $(4.6)$ & - & \multicolumn{2}{|c|}{-} \\
\hline Uninsured & $79 \quad(7.5)$ & $(7.2)$ & $(3.9)$ & $(3.9)$ & - & \multicolumn{2}{|c|}{-} \\
\hline Unknown & $(0.2)$ & $(0.2)$ & $(0.4)$ & $(0.4)$ & - & \multicolumn{2}{|c|}{-} \\
\hline \multicolumn{8}{|l|}{ Clinical } \\
\hline \multicolumn{8}{|l|}{ Intent } \\
\hline Unintentional & $675 \quad(64.4)$ & $2,963 \quad(64.6)$ & $552 \quad(41.4)$ & $783 \quad(41.7)$ & - & 95 & $(77.2)$ \\
\hline Intentional & $274 \quad(26.2)$ & $1,196 \quad(26.1)$ & $545 \quad(40.8)$ & $759 \quad(40.5)$ & - & 6 & (4.9) \\
\hline Undetermined & $63 \quad(6.0)$ & $(5.6)$ & $(8.5)$ & $(8.5)$ & - & 22 & $(17.9)$ \\
\hline Unknown & $36 \quad(3.4)$ & (3.7) & (9.3) & $(9.3)$ & - & & - \\
\hline Opioid & & & & & & & \\
\hline Methadone & $(4.6)$ & $(4.6)$ & $169 \quad(12.7)$ & $238 \quad(12.7)$ & - & 31 & $(25.2)^{c}$ \\
\hline Other prescription opioids & $726 \quad(69.3)$ & $3,208 \quad(70.0)$ & $746 \quad(55.9)$ & $1,048 \quad(55.8)$ & - & 96 & $(78.1)^{c}$ \\
\hline Unspecified & $274 \quad(26.1)$ & $1,167 \quad(25.4)$ & $419 \quad(31.4)$ & $592 \quad(31.5)$ & - & & - \\
\hline Multidrug poisonings & $284 \quad(27.1)$ & $1,275 \quad(27.8)$ & $619 \quad(46.4)$ & $870 \quad(46.3)$ & - & & - \\
\hline$\geq 1$ chronic condition & $377 \quad(36.0)$ & $1,627 \quad(35.5)$ & $962 \quad(72.1)$ & $1,350 \quad(71.9)$ & - & & - \\
\hline 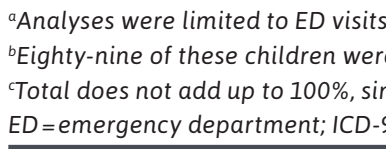 & $\begin{array}{l}\text { ut hospitalization } \\
\text { ates, and } 7 \text { childr } \\
\text { re were cases wit } \\
\text { International Cla }\end{array}$ & $\begin{array}{l}\text { his may have und } \\
\text { had neonatal abs } \\
\text { nore than } 1 \text { opioic } \\
\text { fication of Disease }\end{array}$ & $\begin{array}{l}\text { imated the actuc } \\
\text { nce syndrome dic } \\
\text { olvement. } \\
\text { inth Revision, Cli }\end{array}$ & $\begin{array}{l}\text { umber of pediatr } \\
\text { osis (ICD-9-CM CC } \\
\text { al Modification. }\end{array}$ & $\begin{array}{l}\text { scription op } \\
9.5) \text {. }\end{array}$ & oning & ED visits. \\
\hline
\end{tabular}




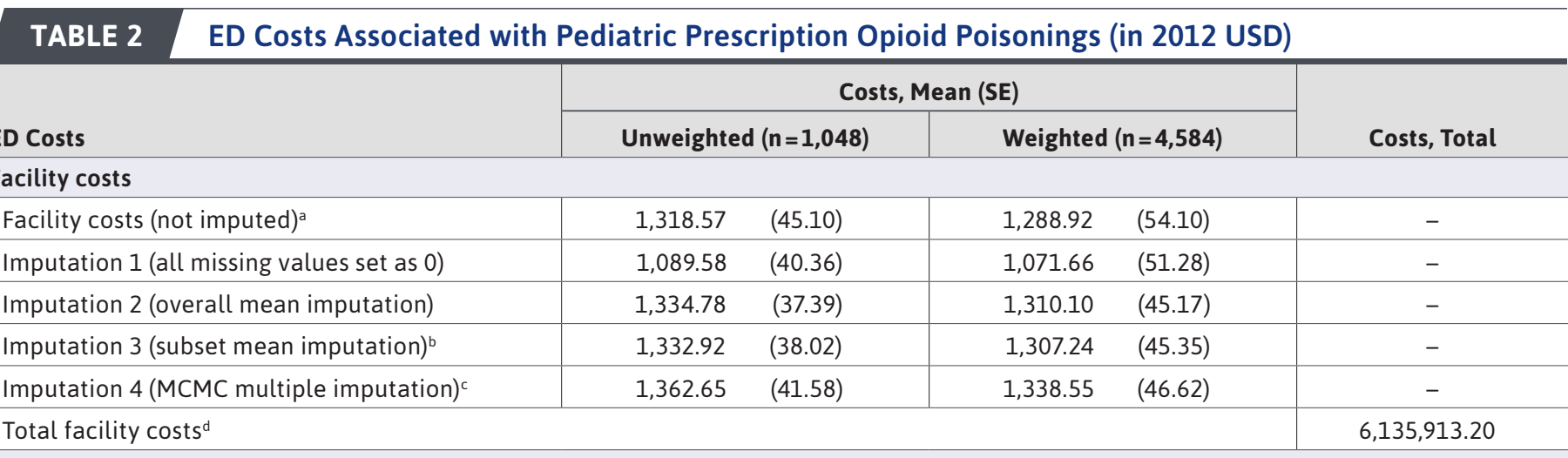

\begin{tabular}{|c|c|c|c|c|c|}
\hline \multicolumn{6}{|l|}{ Physician costs } \\
\hline Physician costs (not imputed)e & 162.88 & $(4.35)$ & 164.88 & $(5.09)$ & - \\
\hline Imputation 1 (all missing values set 0 ) & 110.04 & $(3.77)$ & 107.57 & $(5.37)$ & - \\
\hline Imputation 2 (overall mean imputation) & 162.88 & $(2.94)$ & 164.19 & $(3.32)$ & - \\
\hline Imputation 3 (subset mean imputation) ${ }^{\mathrm{f}}$ & 156.61 & $(3.22)$ & 157.42 & $(3.77)$ & - \\
\hline \multicolumn{5}{|l|}{ Total physician costsg } & $721,613.28$ \\
\hline \multicolumn{5}{|l|}{ Ambulance costs ${ }^{h}$} & $1,050,318.00$ \\
\hline Total ED costs & \multicolumn{2}{|c|}{$1,519.26$} & \multicolumn{2}{|c|}{$1,495.97$} & $7,907,844.48$ \\
\hline
\end{tabular}

${ }^{a} E D$ costs were missing for 182 visits. These were not included in the "not imputed" mean.

${ }^{b}$ Subset based on age group and intent of poisoning.

'The imputation model for ED charges included child's age group; gender; median household income at ZIP-code level of residence location; type of opioid; intent; indicators for multi-drug poisonings, multi-injuries and chronic conditions; number of diagnoses and procedures on record; disposition status; payer; hospital characteristics including hospital region, location, ownership, teaching status, and trauma status; and (nonmissing) ED physician cost.

${ }^{d}$ The base-case estimate of total ED facility costs was based on MCMC imputation and weighted prevalence estimates.

eCPT codes were missing for 340 visits. These were not included in the "not imputed" mean.

'Subset based on age group, intent, and quintiles of (nonmissing) ED physician costs.

${ }^{9} T$ The base-case estimate of physician costs was based on subset mean imputation and weighted prevalence.

${ }^{h}$ For the 4,584 ED visits, we assumed ambulance runs for pediatric patients in the base case to be $50 \%$ (total of 2,292 ED visits) with a cost per ambulance run in 2012 USD $=\$ 458.25$.

$C P T=$ Current Procedural Terminology; $E D=$ emergency department; $M C M C=$ Markov Chain Monte Carlo; USD =U.S dollars .

mean cost of hospitalization from KID. Outliers were examined using the approach described by Friedman et al. (2008). ${ }^{21}$ This consisted of calculating the average charge per day for each stay and identifying the top $1 \%$ of charges per day. The difference between the 75 th percentile and median charge per day was multiplied by 4 and added to the median. This value, $\$ 45,600$ per day, was the cutoff value for suspiciously high charges. Two observations were above this cutoff value and were excluded from cost analyses.

Inpatient facility charges were missing for 20 (1.5\%) inpatient stays. MCMC was used to impute missing values for inpatient stays (Table 3). The imputation model for inpatient charges included child's age group; gender; race; median household income at ZIP code level of residence location; type of opioid; intent; indicators for multidrug poisonings and chronic condition; number of diagnoses and procedures on record; All Patients Refined Diagnosis Related Groups (APR-DRG) severity and mortality risk indices; Elixhauser comorbidities; disposition status; transfer-in and previous ED event indicators; length of stay; payer; and hospital characteristics including hospital region, ownership, bed size, location, and teaching status.

KID does not include CPT codes for inpatient physician costs, so 3 standard CPT codes and their national payment amounts were assumed for all inpatient stays: 99222 "initial hospital care" billed at \$133.09 per day; 99231 "subsequent hospital care" billed at $\$ 38.12$ per day; and 99238 "hospital discharge day" billed at $\$ 69.78$ per day. The national payment amounts for these codes were taken from the CMS 2012 Physician Fee Schedule. ${ }^{20}$ Inpatient stays $\leq 1$ day were assigned CPT codes for initial care (99222) and discharge day care (99238). Inpatient stays $>1$ day were also assigned the 


\section{TABLE 3 Inpatient Costs Associated with Pediatric Prescription Opioid Poisonings (in 2012 USD)}

\begin{tabular}{|c|c|c|c|}
\hline \multirow[b]{2}{*}{ Inpatient Costs } & \multicolumn{2}{|c|}{ Costs, Mean (SE) } & \multirow[b]{2}{*}{ Costs, Total } \\
\hline & $\begin{array}{c}\text { Unweighted } \\
(n=1,332)\end{array}$ & $\begin{array}{l}\text { Weighted } \\
(n=1,874)\end{array}$ & \\
\hline \multicolumn{4}{|l|}{ Facility costs } \\
\hline Facility costs (not imputed) ${ }^{a}$ & $6,624.60(613.53)$ & $6,633.41(630.21)$ & - \\
\hline Imputation 1 (all missing values set as 0 ) & $6,525.13(604.71)$ & $6,537.48(622.68)$ & - \\
\hline Imputation 2 (mean cost/day imputation) & $6,623.42(604.82)$ & $6,632.48(621.48)$ & - \\
\hline Imputation 3 (MCMC multiple imputation) ${ }^{\mathrm{b}}$ & $6,759.91 \quad(607.26)$ & $6,766.03 \quad(624.07)$ & - \\
\hline \multicolumn{3}{|l|}{ Total hospital costs ${ }^{c}$} & $12,679,540.22$ \\
\hline Physician costs & 279.63 & 279.18 & $523,183.32$ \\
\hline Total inpatient costs ${ }^{c}$ & $7,039.54$ & $7,045.21$ & $13,202,723.54$ \\
\hline \multicolumn{4}{|c|}{$\begin{array}{l}\text { Note: Total costs=Weighted mean cost } \times \text { Weighted prevalence }(\mathrm{N}) \text {. } \\
\text { a Inpatient costs were missing for } 20(1.5 \%) \text { stays and were not included in the not imputed mean. } \\
\text { 'The imputation model for inpatient charges included child's age group; gender; race; median household income at ZIP-code level of residence location; type of } \\
\text { opioid; intent; indicators for multidrug poisonings and chronic condition; number of diagnoses and procedures on record; APR-DRG severity and mortality risk } \\
\text { indices; Elixhauser comorbidities; disposition status; transfer-in and previous ED event indicators; length of stay; payer; hospital characteristics including hospital } \\
\text { region, ownership, bed size, location, and teaching status. }\end{array}$} \\
\hline
\end{tabular}

CPT code for subsequent care (99231) for every day between admission and discharge. Total inpatient costs were calculated as the sum of inpatient facility and physician costs.

Ambulance costs, a direct medical cost, were not available in HCUP databases, so we used estimates from the literature. Larkin et al. (2006) estimated ambulance use in about $39 \%$ of injury-related ED visits. ${ }^{22}$ Friedman et al. used a similar estimate. ${ }^{21}$ However, these analyses were not specific to the pediatric population. Adults with opioid poisoning may avoid ED transport for reasons such as fear of legal involvement or discrimination. These reasons may not be a concern for children. Hence, we assumed ambulance runs for the base case to be slightly higher at $50 \%$. This estimate was multiplied by cost per ambulance run, $\$ 429$ in 2010, to compute total ambulance costs. ${ }^{23}$ Total direct medical costs were calculated as the sum of total ED costs and total inpatient costs.

We estimated indirect costs for pediatric patients who died from opioid poisoning as the present value of expected future productivity (PVFP), which included earnings and household services. PVFPs were obtained from Grosse et al. (2009). ${ }^{24}$ A discount rate of $3 \%$ was used..$^{25}$ The 2012 MCOD was used to estimate pediatric deaths from opioid poisonings. Records of decedents aged less than 18 years with a poisoning-related International Classification of Diseases, Tenth Revision, Clinical Modification (ICD-10-CM) code in the cause of death field were extracted (ICD-10-CM code $\mathrm{X} 42$, X44, X62, X64, Y12, or Y14). From these records, decedents who had an indication of opioid as a contributing cause of death were identified using the opioid-specific ICD-10-CM code in the record axis fields (T40.0, T40.2, or T40.3).

We estimated indirect costs for caregivers as the product of days lost from productive activity and average daily production value (DPV). ${ }^{24}$ DPV is the sum of daily market production and daily household production, and it was obtained from Grosse et al. ${ }^{24}$ Indirect costs for ED visits and inpatient stays were calculated as the product of absent days, DPV, and the weighted number of visits. DPV values were reported in 2007 USD and inflated to 2012 USD using the BLS Employment Cost Index for all civilian workers. ${ }^{18}$ The DPV in 2012 USD was estimated at \$142.99. We assumed 1 recovery day per ED visit. Recovery days for inpatient stays were based on the severity of the opioid poisoning. Severity was identified using the APR-DRG severity index in the KID. Average length of stay for inpatient stay was calculated by severity group (none-to-minor, moderate, or major-to-extreme severity). One, 3 , and 7 recovery days were assumed for none to minor, moderate, and major to extreme severity groups, respectively. A maximum of 1 week of recuperation time was assumed based on previous poisoning-related hospital analyses. ${ }^{26,27}$

Multiple one-way sensitivity analyses were performed to examine the effects of assumptions on our estimates 
TABLE 4 Indirect Costs Due to Parent or Caregiver Absenteeism Associated with Pediatric Prescription Opioid Poisonings (in 2012 USD)

\begin{tabular}{|c|c|c|c|c|c|}
\hline & \multicolumn{3}{|c|}{ Absent Days (Mean) ${ }^{b}$} & \multirow{2}{*}{$\begin{array}{l}\text { Weighted } \\
\text { Visits (n) }\end{array}$} & \multirow[b]{2}{*}{ Indirect Costs ${ }^{c}$} \\
\hline & LOS & Recovery ${ }^{d}$ & Total & & \\
\hline ED visit & 1 & 1 & 2 & 4,584 & $1,310,954.64$ \\
\hline \multicolumn{6}{|l|}{ Inpatient stay } \\
\hline None to minor severity ${ }^{a}$ & 1.81 & 1 & 2.81 & 700 & $280,910.94$ \\
\hline Moderate severitya & 2.37 & 3 & 5.37 & 747 & $573,228.99$ \\
\hline Major to extreme severitya & 5.75 & 7 & 12.75 & 427 & $778,586.33$ \\
\hline Total & - & - & - & 1,874 & $1,632,726.26$ \\
\hline \multicolumn{5}{|l|}{ Total } & $2,943,680.90$ \\
\hline
\end{tabular}

a Based on APR-DRG severity of illness assigned in the 2012 KID.

${ }^{b}$ We assumed 1 caregiver per child.

IIndirect costs for ED visits and inpatient stays were calculated as the product of absent days, DPV, and the weighted number of visits. DPV was obtained from Grosse et al..$^{24}$ DPV is defined as the sum of daily market production and daily household production. DPV values were reported in 2007 USD and inflated to 2012 USD, using the BLS Employment Cost Index for all civilian workers. ${ }^{18}$ The DPV in 2012 USD was estimated at $\$ 142.99$.

${ }^{d}$ We assumed 1 recovery day per ED visit. Recovery days for inpatient stays were based on the severity of the opioid poisoning. Severity was identified using the APR-DRG severity index in the KID. Average LOS for inpatient stay was calculated by severity group (none to minor, moderate, or major to extreme severity). One, 3, and 7 recovery days were assumed for none to minor, moderate, and major to extreme severity groups, respectively. A maximum of 1 week of recuperation time was assumed based on previous poisoning-related hospital analyses. ${ }^{26,27}$

APR-DRG = All Patients Refined Diagnosis Related Groups; BLS=Bureau of Labor Statistics; DPV = daily production value; $E D=$ emergency department; $K I D=$ Kids Inpatient Database; $L O S=$ length of stay; USD $=$ U.S. dollars.
(Supplementary Table 1, available in online article). The upper and lower bounds of each parameter were determined based on confidence intervals provided by the data. When a confidence interval was unavailable, the base case was varied based on reasonable assumptions. All analyses were done in SAS version 9.4 (SAS Institute, Cary, NC) and Microsoft Excel 2013 (Microsoft Corp., Redmond WA).

\section{Results}

Pediatric prescription opioid poisoning-related ED visits, inpatient stays, and deaths were most common in patients aged 13-17 years and those in mid to large urban areas. Most were unintentional: $64.6 \%$ of ED visits, $41.7 \%$ of inpatient stays, and $77.2 \%$ of deaths in the weighted population (Table 1).

There was a weighted total of 4,584 (unweighted 1,048) ED visits and 1,874 (unweighted 1,332) inpatient stays for pediatric prescription opioid poisonings in 2012. Mean hospital and physician costs for ED and inpatient visits as calculated by various imputation methods are summarized in Table 2 and Table 3. For the base case, the mean (SE) cost for an ED visit was $\$ 1,496$ (mean facility cost $=\$ 1,339$ [47]; mean physician cost $=\$ 157$ [4]), and the mean cost for an inpatient stay was estimated at $\$ 7,045$ (mean facility cost $=\$ 6,766$ [624]; mean physician cost $=\$ 279$ [6]). Approximately $\$ 13.2$ million (65.8\%) were due to inpatient admissions, while ED visits constituted about \$7.9 million (34.2\%). For the 4,584 ED visits, 2,292 were assumed to have arrived by ambulance. Of the $\$ 7.9$ million, the total ambulance costs of pediatric prescription opioid poisonings were $\$ 1,050,318$ per year (cost per ambulance run in $2012 \mathrm{USD}=\$ 458.25$ ), and this was included in the total costs of ED visits. The total direct medical costs of pediatric prescription opioid poisonings in the United States were estimated to be $\$ 21.1$ million per year.

Total morbidity-related indirect costs in 2012 due to caregiver absenteeism were estimated to be over $\$ 2.9$ million. Inpatient stays constituted about $55.5 \%$ of morbidity-related costs and ED visits accounted for the remainder (Table 4).

The MCOD file indicated that there were 123 pediatric prescription opioid poisoning-related deaths in the United States in 2012. About 69.9\% were teenagers, and $26 \%$ were under the age of 6 years. Total mortality costs were estimated to be $\$ 206.8$ million. Total indirect costs for pediatric prescription opioid poisonings were estimated at approximately \$209.7 million. Mortality-related costs constituted about $98.6 \%$ of this amount. The total costs of pediatric prescription opioid poisonings in the United States were calculated at \$230.8 million.

Cost estimates were most sensitive to the discount rate of PVFP (Figure 1 and Supplementary Table 1, available in online article). Varying the discount rate to $5 \%$ and $10 \%$ (from base-case value of $3 \%$ ) yielded total economic costs of $\$ 146.24$ million and $\$ 69.36$ million, respectively. Differences from base-case estimates were minimal for all other parameters tested.

\section{Discussion}

The estimated mean cost for ED visits and inpatient stays related to pediatric prescription opioid poisonings in the United States were \$1,496 and $\$ 7,045$, respectively, in 2012. As 


\section{FIGURE 1 Total Economic Burden of Opioid Poisonings in Children: One-Way Sensitivity Analyses on Selected Parameters (Tornado Diagram)}

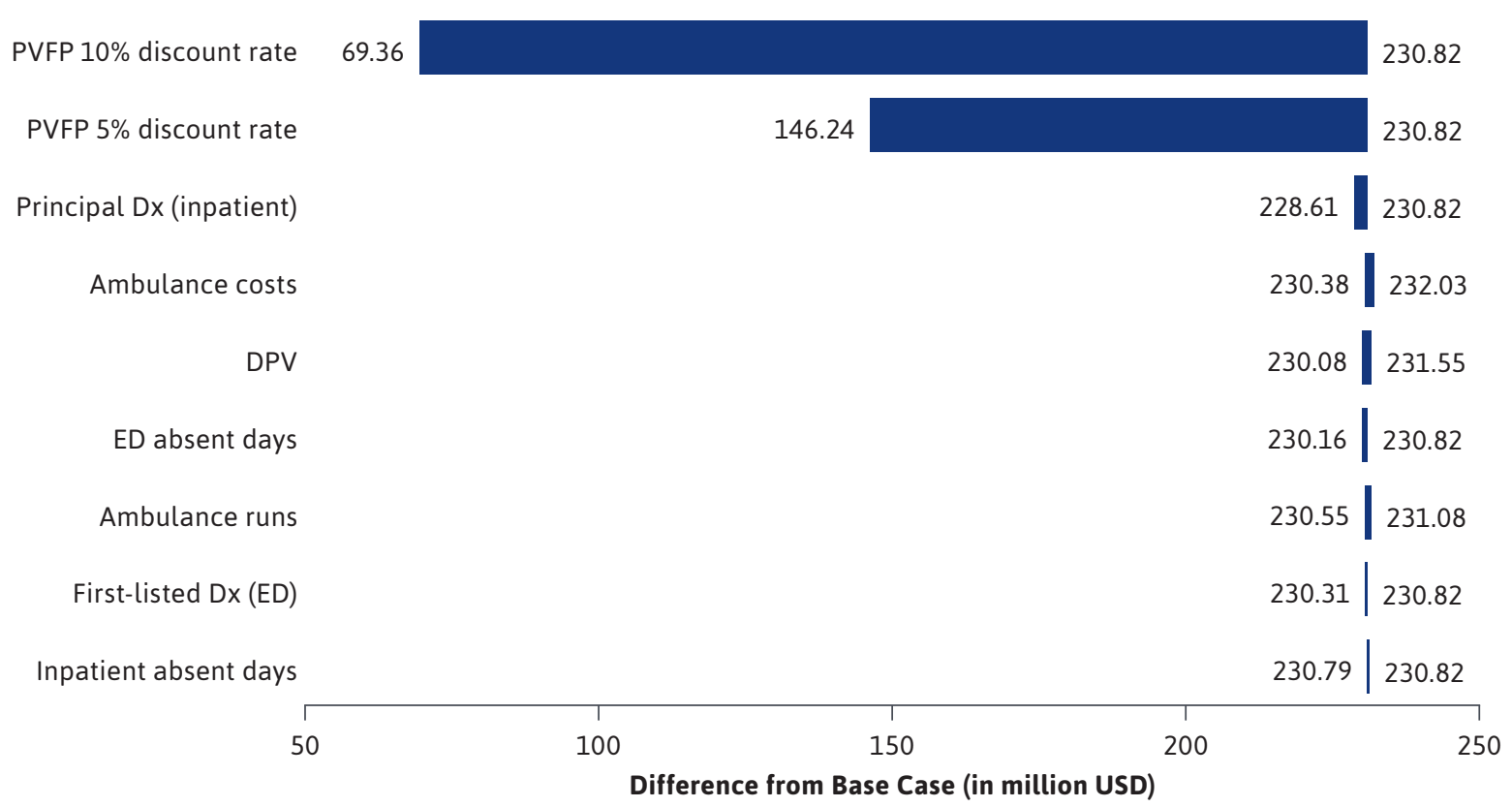

Note: Base-case estimate $=\$ 230.82$ million.

$D P V=$ daily production value; $D x=$ diagnosis; $E D=$ emergency department; PVFP = present value of expected future productivity.

a rough comparison, pediatric opioid poisoning-related inpatient costs are higher than the national mean costs of $\$ 6,415$ for all-hospital stays among pediatric patients..$^{28}$ Four studies have examined the economic burden of opioid poisoning. Xiang et al. (2012) estimated mean charges for drug poisoning-related ED visits at $\$ 2,208$, in 2012 USD. ${ }^{29}$ Yokell et al. calculated mean charges for prescription opioid poisoning ED visits at \$3,833-\$4,339 and mean hospitalization charges at $\$ 31,058-\$ 34,374$, in 2012 USD. ${ }^{9}$ Tadros et al. (2016) estimated mean ED charges at $\$ 1,840$ and mean inpatient charges to be $\$ 14,325$ based on NEDS data from 2006 to $2012 .{ }^{14}$ Inocencio et al. (2013) estimated the mean ED cost to be $\$ 1,967$ and inpatient stay costs to be $\$ 9,696$ in 2011 USD. ${ }^{26}$

Yokell et al., Tadros et al., and Xiang et al. reported charges rather than costs. ${ }^{9,14,29}$ It is well known that hospital and ED charges are substantially higher than costs. Inocencio et al.'s estimates were somewhat higher than those of the current study. However, Inocencio et al.'s estimates were for the general population, not just those aged under 18 years, and included poisonings due to heroin. ${ }^{26}$ Prognosis and management of opioid poisonings in adults can vary considerably from those in children because of factors such as higher prevalence of multiple health conditions, chronic opioid use and misuse, substance use disorders, or polypharmacy. ${ }^{30}$ These factors may result in higher cost of treatment following an opioid poisoning in adults compared with children.

We estimated total direct costs of pediatric prescription opioid poisoning to be $\$ 21$ million and total indirect costs to be nearly \$210 million. Indirect costs consisted of $\$ 2.9$ million due to absenteeism and \$207 million due to premature mortality. In comparison, Inocencio et al. estimated the total direct cost of prescription opioid poisoning in the general population to be $\$ 1.8$ billion and the total indirect cost at $\$ 14.1$ billion. ${ }^{26}$ Indirect costs consisted of absenteeism costs of \$261 million and costs due to premature mortality of about $\$ 14$ billion in 2012 USD. A major factor explaining the large differences is that our estimates represented only pediatric patients, while Inocencio et al.'s estimates represented all ages. The pediatric population represents a very small percentage of the total economic burden of opioid poisoning. Yokell et al. reported that only $4.4 \%$ of patients presenting to EDs for opioid poisonings were aged less than 18 years. ${ }^{9}$ Similarly, Gomes et al. (2018) reported that only $0.2 \%$ of opioid-related deaths in 2016 were in the 0-14 years age group and that $9.5 \%$ were in 
the 15-24 years group. $^{31}$ A recently released report suggests that $0.1 \%$ of opioid-related deaths in 2018 were in those aged $0-14$ years and $8.4 \%$ in those aged $15-24$ years. ${ }^{32}$ In addition, opioid poisonings in adults are more likely to be intentional and severe, resulting in more expensive hospital visits compared with children. ${ }^{33-35}$

While our estimates of direct and indirect costs are small compared with costs in the general population, it seems likely that the intangible costs of poisonings are particularly high in the pediatric population. Poisonings of children result in fear and anxiety in parents and caregivers; poisoningrelated deaths cause overwhelming grief and suffering. Feigelman et al. (2011) have reported that parents who lost a child to a drug overdose experience substantially more grief, stigmatization, and depression than those have lost children to nondrugrelated accidents or natural causes. ${ }^{36}$

Patel et al. (2019) found that the majority of pediatric prescription opioid exposures are unintentional. ${ }^{4}$ Many interventions that could decrease unintentional poisonings, such as safety locks on cabinets, storage of prescription opioids in areas that young children cannot reach, and prescription drug take-back and disposal programs, are relatively inexpensive. As a result, these interventions could be cost-effective despite the relatively low economic burden of pediatric prescription opioid poisonings.

\section{LIMITATIONS}

These analyses have several limitations. The summary CCR data used for ED analyses were from the 2003 HCUP preliminary report. CCRs may have changed since 2003, but there are no updated CCRs. Outcomes and costs related to long-term disability or postdischarge care following an opioid poisoning hospitalization could not be examined in the current data; hence, our study underestimated the true economic burden of pediatric prescription opioid poisonings. CPT codes were not available in the inpatient database, so physician costs associated with hospitalizations were estimated based on several fundamental hospital stay-related CPT codes. Some hospitalizations may have required more physician services. This had minimal effect on the cost estimates, since physician costs were less than $4 \%$ of inpatient costs and less than $0.1 \%$ of direct medical costs. Our study did not include direct nonmedical costs such as meals and accommodations for caregivers. We made assumptions about the proportion of poisonings that would require ambulance runs and the days of productivity caregivers would miss. Our sensitivity analyses indicated these assumptions had negligible effects on our results.

The data used in the study were from 2012. While the prevalence of opioid-related poisonings and the unit cost of medical resources may have changed since then, the results are still useful. For example, our results point out that the vast majority of the costs of opioid-related poisonings is related to premature mortality. By comparison, the costs of ED visits and inpatient stays are relatively small. Further, in the absence of more recent data, the mean cost estimates from this study could be adjusted to current figures using the Consumer Price Index.

\section{Conclusions}

Quantifying the costs of pediatric prescription opioid poisonings can help decision makers understand economic trade-offs in planning interventions. Our study estimated the total economic burden of pediatric prescription opioid poisonings at \$230.8 million in 2012, of which \$21.1 million were from direct medical costs and \$209.7 million from productivity losses. Decision makers should also consider the unmeasured, but probably large, intangible costs in this population.

\section{DISCLOSURES}

This research had no external funding but was funded by an unrestricted research grant made to the Department of Pharmacotherapy \& Outcomes Science by kaléo Pharma, maker of a naloxone product. The authors declare no conflicts of interest or financial interests.

Portions of this study were presented as an abstract at the 22nd Annual ISPOR Meeting; May 22, 2017; Boston, MA.

\section{REFERENCES}

1. Centers for Disease Control and Prevention. CDC's response to the opioid overdose epidemic. Last reviewed January 11, 2019. Accessed November 21, 2020. https://www.cdc.gov/opioids/strategy.html

2. Scholl L, Seth P, Kariisa M, Wilson N, Baldwin G. Drug and opioid-involved overdose deaths - United States, 20132017. MMWR Morb Mortal Wkly Rep. 2019;67(5152);1419-27. doi: 10.15585/mmwr. mm675152e1

3. Gaither JR, Shabanova V, Leventhal JM. US national trends in pediatric deaths from prescription and illicit opioids, 19992016. JAMA Netw Open. 2018;1(8):e186558. doi: 10.1001/jamanetworkopen.2018.6558

4. Patel AM, Wheeler DC, Rose SR, Nadpara PA, Pakyz AL, Carroll NV. Prevalence and characteristics of pediatric opioid exposures and poisonings in the United States. J Pediatr. 2019;206:

148-55.e4. doi: 10.1016/j.jpeds.2018.10.047

5. Boyer EW. Management of opioid analgesic overdose. N Engl J Med. 2012;367(2):146-55. doi: 10.1056/ NEJMra1202561

6. Council of Economic Advisors. The full cost of the opioid crisis: $\$ 2.5$ trillion over four years. October 28, 2019. Accessed November 23, 2020. https://www. whitehouse.gov/articles/full-cost-opioidcrisis-2-5-trillion-four-years/ 
7. Gaither JR, Leventhal JM, Ryan SA, Camenga DR. National trends in hospitalizations for opioid poisonings among children and adolescents, 1997 to 2012. JAMA Pediatr. 2016;170(12):1195-201. doi: 10.1001/jamapediatrics.2016.2154

8. Kane JM, Colvin JD, Bartlett AH, Hall M. Opioid-related critical care resource use in U.S. children's hospitals. Pediatrics. 2018;141(4):e20173335. doi: 10.1542/ peds.2017-3335

9. Yokell MA, Delgado MK, Zaller ND, Wang NE, McGowan SK, Green TC. Presentation of prescription and nonprescription opioid overdoses to US emergency departments. JAMA Internal Medicine. 2014;174(12):2034-47. doi: 10.1001/jamainternmed.2014.5413

10. Healthcare Cost and Utilization Project (HCUP). NEDS database documentation. July 29, 2020. Accessed November 23, 2020. https://www.hcup-us.ahrq.gov/db/ nation/neds/nedsdbdocumentation.jsp

11. Healthcare Cost and Utilization Project (HCUP). KID database documentation. July 29, 2020. Accessed November 23, 2020. https://www.hcup-us.ahrq.gov/db/ nation/kid/kiddbdocumentation.jsp

12. Centers for Disease Control and Prevention. Multiple Cause of Death 19992018. July 29, 2020. Accessed November 23, 2020. https://wonder.cdc.gov/wonder/help/mcd.html

13. Chandwani HS, Strassels SA, Rascati KL, Lawson KA, Wilson JP. Estimates of charges associated with emergency department and hospital inpatient care for opioid abuse-related events. J Pain Palliat Care Pharmacother. 2013;27(3):20613. doi: 10.3109/15360288.2013.803511

14. Tadros A, Layman SM, Davis SM, Bozeman R, Davidov DM. Emergency department visits by pediatric patients for poisoning by prescription opioids. Am J Drug Alcohol Abuse. 2016;42(5):550-55. doi: 10.1080/00952990.2016.1194851

15. Tadros A, Layman SM, Davis SM, Davidov DM, Cimino S. Emergency visits for prescription opioid poisonings. J Emerg Med. 2015;49(6):871-77. doi: 10.1016/j.jemermed.2015.06.035
16. Hansen RN, Oster G, Edelsberg J, Woody GE, Sullivan SD. Economic costs of nonmedical use of prescription opioids. Clin J Pain. 2011;27(3):194-202. doi: 10.1097/ AJP.0b013e3181ff04ca

17. U.S. Bureau of Labor Statistics. Consumer Price Index. Accessed November 23, 2020. https://www.bls.gov/ cpi/\#tables

18. U.S. Bureau of Labor Statistics. Employment Cost Index. Accessed November 23, 2020. http://www.bls.gov/ ect/\#tables

19. Friedman B, Owens P. The cost of "treat and release" visits to hospital emergency departments, 2003. HCUP Methods Series Report\# 2007-05. July 2, 2007. Accessed November 23, 2020. https:// www.hcup-us.ahrq.gov/reports/methods/2007_05.pdf

20. Centers for Medicare \& Medicaid Services. Physician fee schedule. Accessed November 23, 2020. https://www.cms.gov/Medicare/ Medicare-Fee-for-Service-Payment/ PhysicianFeeSched

21. Friedman B, Henke RM, Wier LM. Most expensive hospitalizations, 2008: Statistical Brief \#97. In: Healthcare Cost and Utilization Project. HCUP Statistical Briefs. Agency for Healthcare Research and Quality; 2006. Accessed November 23, 2020. https://www.ncbi.nlm.nih.gov/ books/NBK52651/

22. Larkin GL, Claassen CA, Pelletier AJ, Camargo CA. National study of ambulance transports to United States emergency departments: importance of mental health problems. Prehosp Disaster Med. 2006;21(2):82-90. doi: 10.1017/ S1049023X0000340X

23. U.S. Government Accountability Office. Ambulance providers. Costs and Medicare margins varied widely; transports of beneficiaries have increased. Report to Congressional Committees. GAO-13-6. October 2012. Accessed November 23, 2020. https://www.gao. gov/assets/650/649018.pdf
24. Grosse SD, Krueger KV, Mvundura M. Economic productivity by age and sex: 2007 estimates for the United States. Med Care. 2009;47(7 Suppl 1):94-103.

25. Segel JE. Cost-of-illness studiesa primer. RTI International. January 2006. Accessed November 23, 2020. https://www.researchgate.net/ publication/253434922 Cost-of-Illness Studies-A Primer

26. Inocencio TJ, Carroll NV, Read EJ, Holdford DA. The economic burden of opioid-related poisoning in the United States. Pain Med. 2013;14(10):1534-47. doi: 10.1111/pme.12183

27. Chapman Walsh D, Connor E, Tracey LV, Goldberg GA, Egdahl RH. Posthospital convalescence and return to work. Health Aff (Millwood). 1989;8(3): 76-90. doi: 10.1377/hlthaff.8.3.76

28. Witt WP, Weiss AJ, Elixhauser A. Overview of hospital stays for children, 2012. HCUP Statistical Brief \#187. December 2014. Accessed November 23, 2020. https://www.hcup-us.ahrq.gov/ reports/statbriefs/sb187-Hospital-StaysChildren-2012.pdf

29. Xiang Y, Zhao W, Xiang H, Smith GA. ED visits for drug-related poisoning in the United States, 2007. Am J Emerg Med. 2012;30(2):293-301. doi: 10.1016/j. ajem.2010.11.031

30. Kalapatapu RK, Sullivan MA. Prescription use disorders in older adults. Am J Addict. 2010;19(6):515-22. doi: 10.1111/j.1521-0391.2010.00080.x

31. Gomes T, Tadrous M, Mamdani MM, Paterson JM, Juurlink DN. The burden of opioid-related mortality in the United States. JAMA Netw Open. 2018;1(2):e180217. doi: 10.1001/jamanetworkopen.2018.0217

32. Wilson N, Kariisa M, Seth P, Smith H, Davis NL. Drug and opioid-involved overdose deaths - United States, 20172018. MMWR Morb Mortal Wkly Rep. 2020;69(11):290-97. doi: 10.15585/mmwr. mm6911a4 
33. Coben JH, Davis SM, Furbee PM, Sikora RD, Tillotson RD, Bossarte RM. Hospitalizations for poisoning by prescription opioids, sedatives, and tranquilizers. Am J Prev Med. 2010;38(5):517-24. doi: 10.1016/j.amepre.2010.01.022

34. Hasegawa K, Espinola JA, Brown DFM, Camargo CA. Trends in U.S. emergency department visits for opioid overdose, 1993-2010. Pain Med. 2014;15(10):1765-70. doi: 10.1111/pme.12461
35. Mack KA, Jones CM, Paulozzi LJ. Vital signs: overdoses of prescription opioid pain relievers and other drugs among women - United States, 1999-2010. Morb Mortal Wkly Rep. 2013;62(26):537-42.
36. Feigelman W, Jordan JR, Gorman BS. Parental grief after a child's drug death compared to other death causes: investigating a greatly neglected bereavement population. Omega J Death Dying. 2011;63(4):291-316. doi: 10.2190/OM.63.4.a

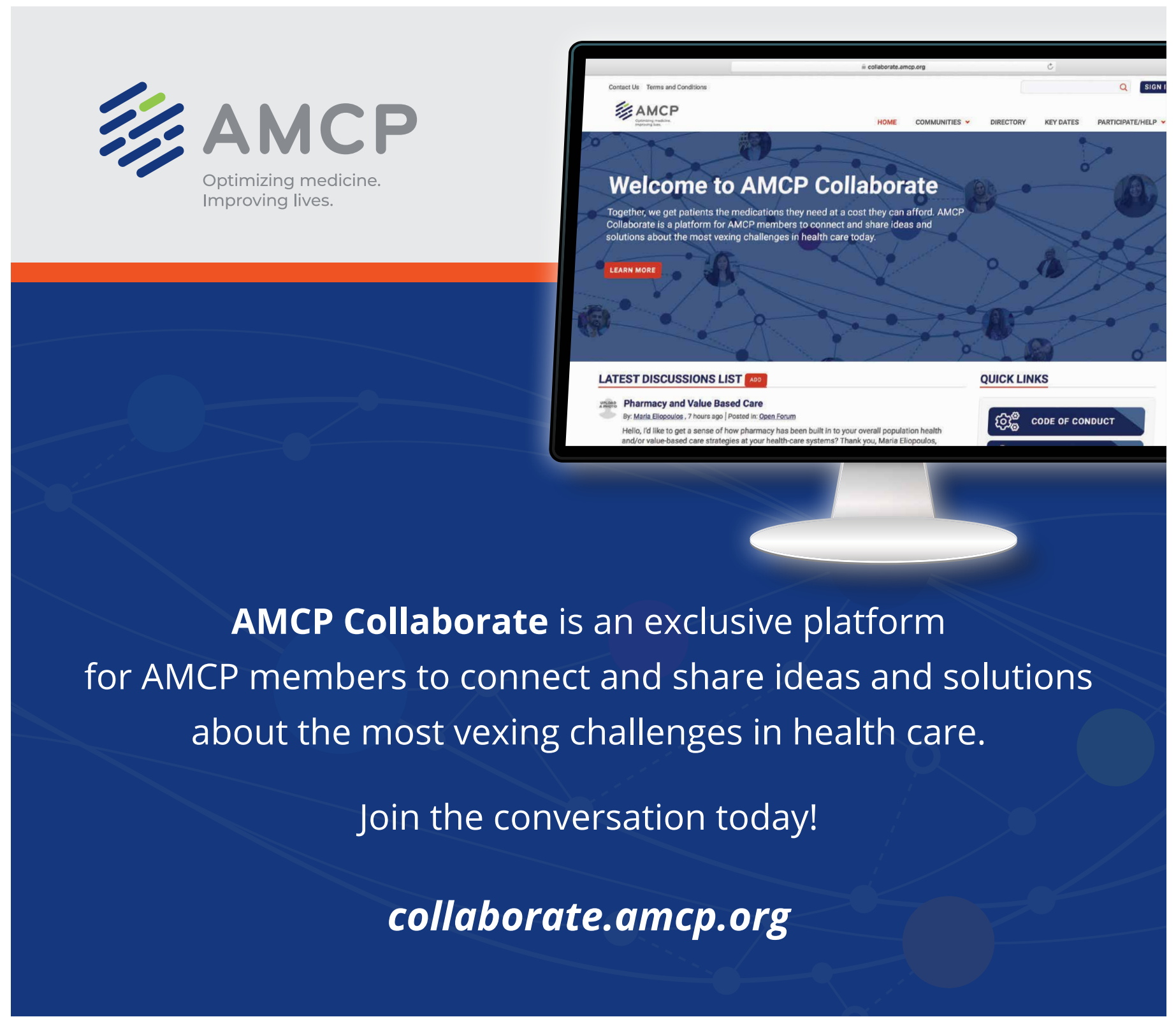

